\title{
Pathological gambling subtypes: A comparison of treatment-seeking and non-treatment-seeking samples from Brazil and Canada
}

\author{
D.S.S. Lobo ${ }^{\text {a,b,1,* }}$, L.C. Quilty ${ }^{\text {c,1 }}{ }^{\text {, S.S. Martins }}{ }^{\mathrm{d}}$, H. Tavares $^{\mathrm{e}}$, H. Vallada ${ }^{\mathrm{f}}$, J.L. Kennedy ${ }^{\text {b,g }}$, R.M. Bagby ${ }^{\text {h,i }}$ \\ a Addictions Program and Neurogenetics Laboratory, Centre for Addiction and Mental Health, 33 Russell St., R3020, Toronto, ON M5S 2S1, Canada \\ ${ }^{\mathrm{b}}$ Department of Psychiatry, University of Toronto, 250 College St., R129, Toronto, ON M5T 1R8, Canada \\ c Clinical Research Department, Centre for Addiction and Mental Health, 250 College St., $R$ 648, Toronto, ON M5T 1R8, Canada \\ d Department of Epidemiology, Mailman School of Public Health, Columbia University, 722 West 168th Street, Rm. 509, New York, NY 10032, USA \\ e Gambling Outpatient Unit, Department of Psychiatry, University of São Paulo, Rua Dr. Ovídio Pires de Campos, 785, São Paulo, SP 05403-903, Brazil \\ ${ }^{\mathrm{f}}$ Department of Psychiatry, University of São Paulo Medical School, Rua Dr. Ovídio Pires de Campos, 785, São Paulo, SP 05403-903, Brazil \\ ${ }^{g}$ Neurogenetics Laboratory, Centre for Addiction and Mental Health, Toronto, Canada \\ ${ }^{\mathrm{h}}$ Departments of Psychology and Psychiatry, University of Toronto, Canada \\ ${ }^{i}$ Research Program, Centre for Addiction and Mental Health, 1265 Military Trail, Toronto, ON M1C 1A4, Canada
}

\section{A R T I C L E I N F O}

Available online 12 March 2014

\section{Keywords:}

Pathological gambling

Gambling subtypes

Personality

Problem gambling

\begin{abstract}
A B S T R A C T
Background: Pathological gambling (PG) is a heterogeneous disorder. The identification and characterization of PG subtypes could lead to tailored treatment approaches, which may, in turn, improve treatment outcomes. Objective: To investigate PG subtypes based on personality traits across two different cultural and clinical settings. Consistent with the Pathways Model, we hypothesized the presence of three subtypes (behaviorally conditioned $-\mathrm{BC}$, emotionally vulnerable $-\mathrm{EV}$, and antisocial impulsivist $-\mathrm{AI}$ ).

Methods: 140 PG adults from São Paulo, Brazil (SP sample) and 352 adults with PG $(n=214)$ or sub-clinical PG $(n=138)$ from Toronto, Canada (TO sample) completed the Temperament and Character Inventory (TCI). Latent-class analysis was used to investigate subtypes.

Results: A 2-class solution was the best model for the pooled SP and TO samples. Class 1 presented a normative personality profile and was composed exclusively of participants from Toronto (BC subtype). Class 2 was characterized by high novelty seeking, high harm avoidance, and low self-directedness, and included participants from both SP and TO (EV subtype). When sub-clinical PGs were excluded from the analysis, a single-class solution better characterized the SP and TO samples.

Conclusions: Our results suggest that PG severity, rather than community or clinical settings, may have an effect on PG subtypes. The generalizability of the results is limited by the demographic and clinical features of the selected samples. Future neurobiological studies may contribute to the categorization of subjects into PG subtypes based on different underlying biological pathways.
\end{abstract}

(C) 2014 Elsevier Ltd. All rights reserved.

\section{Introduction}

Several studies have proposed that the identification of pathological gambling (PG) subtypes may be an important factor in the development of more specific treatment strategies (Blaszczynski \& Nower, 2002; Ledgerwood \& Petry, 2010; Milosevic \& Ledgerwood, 2010). Blaszczynski and Nower (2002) proposed "the pathways model" for the development of PG, which has been generally investigated in terms of three PG subtypes: (1) behaviorally conditioned (BC),

\footnotetext{
* Corresponding author at: 33 Russell St., R3020, Toronto, ON M5S 2S1, Canada. Tel.: + 1 $4165358501 \times 6568$

E-mail addresses: Daniela.Lobo@camh.ca (D.S.S. Lobo), Lena.Quilty@camh.ca (L.C. Quilty),ssm2183@columbia.edu (S.S. Martins), hermanot@uol.com.br (H. Tavares), homero.vallada@gmail.com (H. Vallada),Jim.Kennedy@camh.ca (J.L. Kennedy), rmichael.bagby@utoronto.ca (R.M. Bagby).

${ }^{1}$ Equal contributions as first authors.
}

(2) emotionally vulnerable (EV), and (3) antisocial impulsivist (sic) (AI). Overall, studies have confirmed the pathways model subtypes; however, questions remain as to whether subtypes that have been identified in community samples can also be identified in clinical samples (Milosevic \& Ledgerwood, 2010; Slutske, Caspi, Moffitt, \& Poulton, 2005). This is a critically important issue as most individuals who develop PG never seek treatment. Further, studies to date have been performed in English-speaking countries and predominantly Anglo-Saxon cultures (i.e., U.S., Canada, and Australia), such that little information is available regarding PG subtypes in other language groups and cultures.

The Temperament and Character Inventory (TCI) (Cloninger, Svrakic, \& Przybeck, 1993) has been extensively used in psychiatry research (Albayrak, Ekinci, \& Caykoylu, 2012; Goekoop, De Winter, \& Goekoop, 2011; Kampman \& Poutanen, 2011; Sarisoy et al., 2012). To date, two published studies have identified four PG subtypes using the TCI, with the first study using a community-based sample (Turner, 
Jain, Spence, \& Zangeneh, 2008) and the second study using a clinical sample (Alvarez-Moya et al., 2010).

Our objective was to investigate PG subtypes based on the TCI in two different countries (Brazil and Canada) from two different samples - a treatment-seeking PG sample recruited from a clinical setting and a sample of non-treatment-seeking PGs, recruited from a community setting. We hypothesized that we would identify three PG subtypes consistent with Blaszczynski and Nower (2002) in both settings. We expected the BC subtype to be characterized by normative TCI trait levels, whereas both the EV and AI subtypes would be characterized by high Novelty Seeking and low Self-Directedness which are correlated with impulsivity measures (Piero, 2010; Yoo et al., 2006). We expected that Harm Avoidance would differentiate the EV and AI subtypes because it has been significantly associated with mood and anxiety disorders (Cloninger, Zohar, Hirschmann, \& Dahan, 2012). We also hypothesized that the EV and AI subtypes would be found more frequently in the treatment-seeking sample, whereas the BC subtype would be more frequent in the community sample.

\section{Methods}

\subsection{Sample and assessments}

Pathological gamblers seeking treatment at the University of São Paulo (Tavares, Gentil, Oliveira, \& Tavares, 1999) (Brazil) between 2001 and 2004 were invited to participate in a PG study (da Silva Lobo et al., 2007). In the São Paulo sample (SP sample) individuals who met $\geq 5$ DSM-IV diagnostic criteria for PG were included the study. Psychiatric comorbidities were assessed through the Schedules for Clinical Assessment in Neuropsychiatry (SCAN) (Wing et al., 1990).

Adult gamblers from Toronto (Canada) were recruited from the general population between 2003 and 2006. Both sub-clinical pathological gamblers (1-4 DSM-IV criteria) and individuals meeting full DSM-IV diagnostic criteria for PG ( $\geq 5$ DSM-IV criteria) were included in the TO sample. Psychiatric comorbidities were assessed through the Structured Clinical Interview for DSM-IV-TR Axis I Disorders, non-patient version - SCID-I/NP (First, Spitzer, Gibbon, \& Williams, 2002).

In both the SP and TO samples, gambling status was ascertained through a DSM-IV based interview (NODS) (N.O.R.C., 1999) and lifetime history of psychoses, bipolar disorder and neurological diseases were exclusion criteria.

The Temperament and Character Inventory - TCI (Cloninger et al., 1993; Fuentes, Tavares, Camargo, \& Gorenstein, 2000) was used to assess personality characteristics in both samples. The TCI is composed of 4 temperament (Novelty Seeking - NS, Harm Avoidance - HA, Reward Dependence - RD, and Persistence $-\mathrm{P}$ ) and 3 character scales (SelfDirectedness - SD, Cooperativeness - C, and Self-Transcendence - ST).

\subsection{Statistical analyses}

Because the TO sample included sub-clinical pathological gamblers, we carried out analyses using all participants as well as only those meeting the DSM-IV criteria for PG (TO PG Only sample, $n=214$ ).

Socio-demographic data and TCI scores from the SP, TO and TO PG Only samples were analyzed using chi-squared tests, $t$-tests or ANCOVAs as appropriate. The LCA approach developed by Fraley and Raftery $(2002,2006)$ was used to investigate the presence of classes in each of the samples. Statistical analyses were performed using MPlus 6.0 (Muthén \& Muthén, 1998-2010). The best-fit model was selected based primarily on the lower values of the Bayesian Information Criterion (BIC) statistic while taking into consideration other indices (AIC, adjusted-BIC, Lo-Mendell-Rubin test - LMRT, bootstrap likelihood ratio test - BLRT, and entropy), class sizes and convergence of the model (Nylund, Asparouhov, \& Muthen, 2007). Sample origin was included as a covariate to determine whether the class solution differed across samples or whether the probability of membership in a particular class differed across samples. In the event of more than one class, chi-square tests based on the log-likelihood difference associated with models determined whether classes differed in their mean scores on each TCI scale where a) the group means on a particular scale are assumed to be the same in each class vs. b) the mean scores are allowed to differ across classes.

\section{Results}

\subsection{Socio-demographic characteristics and TCI scores}

\subsubsection{SP $\times$ TO samples}

Compared with the TO sample, the SP sample presented a higher proportion of females $\left(\chi^{2}(d f)=8.4(1), p<.001\right)$; and of individuals who were married or living with a partner $\left(\chi^{2}(d f)=31(1), p<.001\right)$, who were employed $\left(\chi^{2}(d f)=17(3), p=.001\right)$, and who presented higher PG severity (corrected for gender, $F(d f)=151.5(1), p<.001$, $d=1.3$ ). The TO sample presented a higher proportion of individuals who completed high school $\left(\chi^{2}=5, d f=1, p=.02\right)$.

The SP sample exhibited higher scores on NS $(F(d f)=22.7(1)$, $p<.001, d=0.5)$ and HA $(F(d f)=26.8(1), p<.001, d=0.3)$, and lower scores on SD $(F(d f)=19.4(1), p<.001, d=0.4)$ after controlling for gender and PG severity.

\subsection{2. $S P \times$ TO PG Only samples}

Compared with the TO PG Only sample, the SP sample presented a higher proportion of females $\left(\chi^{2}(d f)=19(1), p<.001\right)$, and of individuals who were married or living with a partner $\left(\chi^{2}(d f)=41(1)\right.$, $p<.001)$, and who were employed $\left(\chi^{2}(d f)=23(3), p<.001\right)$. PG was also more severe in the SP sample (corrected for gender, $F(d f)=$ 46.8(1), $p<.001, d=.7$ ).

Finally, the SP sample presented higher scores on NS $(F(d f)=$ 26.8(1), $p<.001, d=.6)$ and HA $(F(d f)=7.8(1), p=.005, d=.6)$, and lower scores on $\mathrm{SD}(F(d f)=17.1(1), p<.001, d=.4)$ after controlling for gender and PG severity.

\subsection{Psychiatric comorbidity and types of gambling}

No psychiatric comorbidity diagnosis data was available for the TO sample but individuals with positive screenings on depression, anxiety and substance abuse as assessed by the SCID N/P were included in the study. No psychotic, bipolar, or neurological disorders were present.

In the SP sample $80 \%(n=112)$ of the subjects presented with tobacco dependence, $67 \%(\mathrm{n}=94)$ presented with major depression, $12.9 \%(n=18)$ presented with alcohol dependence, $6.4 \%(n=9)$ presented with obsessive-compulsive disorder, and 5.7\% $(n=8)$ presented with panic disorder. The elevated rate of psychiatric comorbidity in the SP sample is consistent with rates found in other treatmentseeking (Crockford \& el-Guebaly, 1998; Petry, Stinson, \& Grant, 2005) and general population samples of PG (Lorains, Cowlishaw, \& Thomas, 2011).

\subsection{Latent class analyses}

A series of solutions consisting of 1 to 5 classes were fit within each of the individual samples (SP, TO and TO PG Only). Our results indicate that no subtypes exist in any of the three individual samples (results available upon request).

\subsubsection{Pooled SP and TO samples}

The "best-fitted" model was the 2 -class solution (Table 1 ), according to BIC and LMRT statistics. Class 1 is composed 316 subjects from the TO sample. Class 2 consists of 176 subjects and is composed of the entire SP sample ( $n=140,79.5 \%)$ and a proportion of the TO sample $(n=36$, $20.5 \%$ ). Because sample origin and treatment-seeking status are 
Table 1

Latent class analyses for the pooled São Paulo (SP) and Toronto (TO) samples and for the pooled SP and Toronto Pathological Gambling Only (TO PG Only) samples.

\begin{tabular}{|c|c|c|c|c|c|c|c|c|}
\hline Number of classes & Log likelihood & AIC & $\mathrm{BIC}$ & Adjusted BIC & LMRT & BLRT & Class size & Entropy \\
\hline \multicolumn{9}{|c|}{ Pooled SP $(n=140)$ and TO samples $(n=352)$} \\
\hline 1 Class & $-10,328$ & 20,726 & 20,873 & $20,761.9$ & $\mathrm{n} / \mathrm{a}$ & $\mathrm{n} / \mathrm{a}$ & 492 & $\mathrm{n} / \mathrm{a}$ \\
\hline 2 Classes & $-10,248.8$ & $20,585.6$ & $20,770.3$ & $20,630.6$ & $p<0.001$ & $p<0.0001$ & $316 / 176$ & 0.7 \\
\hline 3 Classes & $-10,231.9$ & $20,569.8$ & $20,792.3$ & $20,624.1$ & $p=0.43$ & $p=0.02$ & $200 / 118 / 174$ & 0.6 \\
\hline 4 Classes $^{\mathrm{a}}$ & $-10,212.9$ & $20,549.9$ & $20,810.2$ & $29,613.4$ & $p=0.33$ & $p<0.0001$ & $43 / 148 / 135 / 166$ & 0.7 \\
\hline 5 Classes $^{\mathrm{a}}$ & $-10,198.9$ & $20,539.9$ & 20,838 & $20,612.6$ & $p=0.09$ & $p=0.17$ & $1 / 65 / 122 / 128 / 176$ & 0.7 \\
\hline \multicolumn{9}{|c|}{ Pooled SP $(n=140)$ and TO PG Only samples $(n=214)$} \\
\hline 1 Class & -7362.1 & $14,794.1$ & $14,929.5$ & $14,818.5$ & $\mathrm{n} / \mathrm{a}$ & $\mathrm{n} / \mathrm{a}$ & 354 & $\mathrm{n} / \mathrm{a}$ \\
\hline 2 Classes & 7313.6 & $14,715.1$ & $14,885.4$ & $14,745.8$ & $p=0.21$ & $p<0.0001$ & $196 / 158$ & 0.6 \\
\hline 3 Classes $^{\mathrm{a}}$ & -7295.5 & $14,697.4$ & $14,902.5$ & $14,734.4$ & $p<0.001$ & $p=0.02$ & $1 / 197 / 156$ & 0.8 \\
\hline 4 Classes $^{\mathrm{b}}$ & - & - & - & - & - & - & - & - \\
\hline 5 Classes $^{\mathrm{b}}$ & - & - & - & - & - & - & - & - \\
\hline
\end{tabular}

$\mathrm{AIC}=$ Akaike Information Criterion, BIC = Bayesian Information Criterion, LMRT = Lo-Mendell-Rubin test, BLRT = bootstrap likelihood ratio test.

a Classes presenting convergence and/or estimation problems.

b Solutions for models with 4 and 5 classes could not be estimated for the pooled SP and TO PG only samples.

confounded in these samples, we cannot determine whether the classes are equally likely to occur in both samples.

As shown in Table 2, Class 1 exhibited lower NS and HA scores, and higher SD scores compared with Class 2. Class 1 exhibited normative mean scores (Cloninger et al., 1993) on all scales, suggesting that this class presents a more adaptive personality profile. Class 2 exhibited SD mean scores that are more than one standard-deviation below, and NS and HA mean scores that are approximately one standard-deviation above the upper limit of normative data (Cloninger et al., 1993). All other TCI scales on Class 2 are within the range of normative data.

Class 2 presents a higher proportion of females $\left(\chi^{2}(d f)=8.2(1)\right.$, $p=.004)$, and of individuals who were employed $\left(\chi^{2}(d f)=11.3(3)\right.$, $p=.01)$, who lived with a partner $\left(\chi^{2}(d f)=17.5(1), p<.001\right)$, and who did not complete high school $\left(\chi^{2}(d f)=6.4(1), p=.01\right)$. Class 1 presents lower PG severity compared to Class 2 (corrected for gender, $F(d f)=168.1(1), p<.001)$.

\subsubsection{Pooled SP and TO PG Only samples}

Table 1 presents the results for the LCA in the pooled SP and TO PG Only samples. Convergence problems were observed in solutions with 3-5 classes, which prevent us from using the BIC to interpret the results. Both of the LRTs suggest that the data is best described by a single-class solution.

\section{Discussion}

Consistent with our hypotheses, we found a BC subtype characterized by normative TCI trait levels (Class 1 ), and an EV subtype characterized by higher NS and HA and lower SD compared to normative TCI trait levels (Class 2). Contrary to our hypotheses, we did not find a class representative of the AI subtype. The fact that we did not find PG

Table 2

TCI Personality Scale Scores in the pooled Toronto (TO) and São Paulo (SP) samples according to class obtained through latent class analysis, chi-square tests of the difference in log-likelihood ratios associated with each class. Significant results highlighted in bold.

\begin{tabular}{lcccc}
\hline TCI scales & $\begin{array}{l}\text { Class 1 } \\
(n=316) \\
\text { mean }( \pm S E)\end{array}$ & $\begin{array}{l}\text { Class 2 } \\
(n=176) \\
\text { mean }( \pm S E)\end{array}$ & $\begin{array}{l}\text { Log-likelihood } \\
\chi^{2}\end{array}$ & $p$ \\
\hline Temperament & & & & \\
Novelty Seeking (NS) & $20.3(0.6)$ & $25.7(0.8)$ & $\mathbf{9 9 . 3}$ & $<\mathbf{0 . 0 0 0 1}$ \\
Harm Avoidance (HA) & $14.1(0.6)$ & $18.9(0.6)$ & $\mathbf{8 . 3}$ & $<\mathbf{0 . 0 0 4}$ \\
Reward Dependence (RD) & $14.0(0.3)$ & $13.6(0.4)$ & 0.3 & 0.6 \\
Persistence (P) & $4.9(0.1)$ & $4.3(0.2)$ & 3.3 & 0.1 \\
& & & & \\
Character & & & & $\mathbf{0 . 0 0 0 1}$ \\
Self-Directedness (SD) & $28.0(0.8)$ & $19.5(0.9)$ & $\mathbf{1 9 . 5}$ & 0.8 \\
Cooperativeness (C) & $28.8(0.5)$ & $28.5(0.7)$ & 0.1 & 0.5 \\
Self-Transcendence (ST) & $16.9(0.4)$ & $17.5(0.6)$ & 0.4 & \\
\hline
\end{tabular}

subtypes when sub-clinical PG was excluded suggests that samples with a restricted range of PG symptomatology may not exhibit the same subtypes found in more varied samples. Indeed, a previous investigation supporting personality-based subtypes of PG similarly included participants with both PG as well as diagnostically subthreshold or non-problematic levels of gambling involvement (e.g., Vachon \& Bagby, 2009).

Two previous studies have used the TCI for the characterization of PG subtypes (Alvarez-Moya et al., 2010; Turner et al., 2008). Turner et al.'s (2008) emotional vulnerability subtype, characterized by high impulsiveness and HA, and low SD is very similar to our Class 2. Alvarez-Moya et al.'s (2010) "disorganized and emotionally unstable" subtype presents high scores on NS, HA and ST and low scores on SD and C, which partially corresponds to our Class 2; whereas the "high functioning" subtype presents a well-adapted personality profile, similar to our Class 1 .

Studies that characterized subtypes of PG using impulsivity scales have found a subtype characterized by emotional dysregulation and low impulsivity levels (Milosevic \& Ledgerwood, 2010), while others have found an emotional dysregulation subtype presenting high levels of impulsivity and/or boredom proneness similar to our Class 2 (Alvarez-Moya et al., 2010; Blaszczynski, McConaghy, \& Frankova, 1990; Graham \& Lowenfeld, 1986; Lesieur, 2001; Turner et al., 2008; Vachon \& Bagby, 2009). Together with our TCI data, the psychopathological profile of the SP sample indicates that Class 2 is indeed similar to the PG subtype characterized by high impulsivity and emotional dysregulation described by other studies in both community (Turner et al., 2008; Vachon \& Bagby, 2009) and treatment-seeking samples (Blaszczynski et al., 1990; Graham \& Lowenfeld, 1986; Lesieur, 2001).

Another commonly identified PG subtype is one characterized by higher levels of impulsivity and low levels of psychopathology (Alvarez-Moya et al., 2010; Bonnaire, Bungener, \& Varescon, 2009; Gonzalez-Ibanez et al., 2003; Ledgerwood \& Petry, 2006; Steel \& Blaszczynski, 1996). Several issues could have contributed to the fact that we did not find this subtype in the samples we studied: a) axis I comorbidity was not available for the TO sample, precluding the ability to evaluate variability in clinical features; and b) subjects in the SP sample were very similar regarding educational level and socio-demographic status (da Silva Lobo et al., 2007) and thus the SP sample might have less variability compared to other treatment samples. These limitations, including the fact that we did not examine the influence of gender (due to insufficient power) in our models should be considered in the interpretation of our results.

Although legalized gambling in Canada and Brazil share important similarities, we cannot rule out the possibility of a confounding effect of culture on our results. Moreover, we cannot rule-out the possible effect of sample origin on inferences regarding the effect of treatmentseeking and non-treatment-seeking samples on PG subtypes. In order to address this issue, it would be necessary for both samples to have 
the same treatment-seeking status - a challenging issue as very few PG subjects seek treatment.

Nevertheless, the fact that no subtypes were found when only pathological gamblers were analyzed suggests that PG severity, rather than community or clinical setting, may have an effect on PG subtypes, an interpretation partially corroborated by a recent study (Knezevic $\&$ Ledgerwood, 2012).

Replication in large samples and additional clinical and community settings can further clarify these issues, and enhance the successful execution of neurobiological and genetic investigations of PG through the identification of more phenotypically homogenous PG subtypes (Lobo \& Kennedy, 2009).

\section{Role of Funding Sources}

Contributors Study concept and design: Daniela Lobo, Hermano Tavares, James Kennedy Acquisition of data: Brazil sample was collected by Drs. Lobo, Martins and Tavares under the supervision of Dr. Vallada. The Toronto sample was collected by Dr. Kennedy.

\section{Contributors}

Analysis and interpretation of data: Daniela Lobo, Lena Quilty, Michael Bagby Critical revision of the manuscript for important intellectual content: Drs. Daniela Lobo, Lena Quilty, Silvia Martins, Homero Vallada, Hermano Tavares, Michael Bagby and James Kennedy.

\section{Conflict of interest}

The authors declare that they have no conflicts of interest.

\section{Acknowledgments}

We would like to thank Prof. Valentim Gentil for revising previous versions of this manuscript and Ms. Tamara Arenovich for reviewing the statistical analyses. We would also like to acknowledge the Fundação de Amparo a Pesquisa do Estado de São Paulo (FAPESP) (02/02653-7 and 02/00009-3) and the Ontario Problem Gambling Research Centre (OPGRC) (2277) for providing the funding for this research.

\section{References}

Albayrak, Y., Ekinci, O., \& Caykoylu, A. (2012). Temperament and character personality profile in relation to suicide attempts in patients with schizophrenia. Comprehensive Psychiatry. http://dx.doi.org/10.1016/j.comppsych.2012.04.007 (doi: S0010-440X(12) 00071-5 [pii]).

Alvarez-Moya, E. M., Jimenez-Murcia, S., Aymami, M. N., Gomez-Pena, M., Granero, R., \& Santamaria, J. (2010). Subtyping study of a pathological gamblers sample. Canadian Journal of Psychiatry, 55(8), 498-506.

Blaszczynski, A., McConaghy, N., \& Frankova, A. (1990). Boredom proneness in pathological gambling. Psychological Reports, 67(1), 35-42.

Blaszczynski, A., \& Nower, L. (2002). A pathways model of problem and pathological gambling. Addiction, 97(5), 487-499.

Bonnaire, C., Bungener, C., \& Varescon, I. (2009). Subtypes of French pathological gamblers: Comparison of sensation seeking, alexithymia and depression scores. Journal of Gambling Studies. http://dx.doi.org/10.1007/s10899-009-9142-z.

Cloninger, C. R., Svrakic, D.M., \& Przybeck, T. R. (1993). A psychobiological model of temperament and character. Archives of General Psychiatry, 50(12), 975-990.

Cloninger, C. R., Zohar, A. H., Hirschmann, S., \& Dahan, D. (2012). The psychological costs and benefits of being highly persistent: Personality profiles distinguish mood disorders from anxiety disorders. Journal of Affective Disorders, 136(3), 758-766. http://dx.doi.org/10.1016/j.jad.2011.09.046 (doi: S0165-0327(11)00572-6 [pii]).

Crockford, D. N., \& el-Guebaly, N. (1998). Psychiatric comorbidity in pathological gambling: A critical review. Canadian Journal of Psychiatry, 43(1), 43-50.

da Silva Lobo, D. S., Vallada, H. P., Knight, J., Martins, S. S., Tavares, H., \& Gentil, V. (2007). Dopamine genes and pathological gambling in discordant sib-pairs. Journal of Gambling Studies, 23(4), 421-433.

First, M. B., Spitzer, R. L., Gibbon, M., \& Williams, J. (2002). Structured Clinical Interview for DSM-IV-TR Axis I Disorders, Research Version, Non-patient Edition. (SCID-I/NP). New York: Biometrics Research, New York State Psychiatric Institute.

Fraley, C., \& Raftery, A. E. (2002). Model-based clustering, discriminant analysis and density estimation. Journal of the American Statistical Association, 97, 611-631.

Fraley, C., \& Raftery, A. E. (2006). MCLUST version 3 for R: Normal mixture modeling and model-based clustering. (Vol. Technical Report Number 504). : Department of Statistics, University of Washington.

Fuentes, D., Tavares, H., Camargo, C., \& Gorenstein, C. (2000). Inventário de Temperamento e Caráter de Cloninger - Validação da Versão em Português. In C. Gorestein, L. Andrade,
\& A. Zuardi (Eds.), Escalas de Avaliação Clínica em Psiquiatria e Psicofarmacologia (pp. 363-376). São Paulo: Lemos Editorial.

Goekoop, J. G., De Winter, R. F., \& Goekoop, R. (2011). An increase of the character function of self-directedness is centrally involved in symptom reduction during remission from major depression. Depression Research and Treatment, 2011, 749640. http://dx.doi.org/10.1155/2011/749640.

Gonzalez-Ibanez, A., Aymami, M. N., Jimenez, S., Domenech, J. M., Granero, R., \& LouridoFerreira, M. R. (2003). Assessment of pathological gamblers who use slot machines. Psychological Reports, 93(3 Pt 1), 707-716.

Graham, J. R., \& Lowenfeld, B. H. (1986). Personality dimensions of the pathological gambler. Journal of Gambling Behavior, 2, 58-66.

Kampman, O., \& Poutanen, O. (2011). Can onset and recovery in depression be predicted by temperament? A systematic review and meta-analysis. Journal of Affective Disorders, 135(1-3), 20-27. http://dx.doi.org/10.1016/j.jad.2010.12.021 (doi: S0165-0327(11) 00022-X [pii]).

Knezevic, B., \& Ledgerwood, D.M. (2012 Nov). Gambling severity, impulsivity, and psychopathology: Comparison of treatment- and community-recruited pathological gamblers. American Journal on Addictions, 21(6), 508-515.

Ledgerwood, D.M., \& Petry, N. M. (2006). Psychological experience of gambling and subtypes of pathological gamblers. Psychiatry Research, 144(1), 17-27. http://dx.doi.org/ 10.1016/j.psychres.2005.08.017 (doi: S0165-1781(05)00281-7 [pii]).

Ledgerwood, D.M., \& Petry, N. M. (2010). Subtyping pathological gamblers based on impulsivity, depression, and anxiety. Psychology of Addictive Behaviors, 24(4), 680-688. http://dx.doi.org/10.1037/a0019906 (doi: 2010-18186-001 [pii]).

Lesieur, H. (2001). Cluster analysis of types of inpatient pathological gamblers. Dissertation Abstracts International, 62B, 2065

Lobo, D. S., \& Kennedy, J. L. (2009). Genetic aspects of pathological gambling: a complex disorder with shared genetic vulnerabilities. Addiction, 104(9), 1454-1465. http:// dx.doi.org/10.1111/j.1360-0443.2009.02671.x.

Lorains, F. K., Cowlishaw, S., \& Thomas, S. A. (2011). Prevalence of comorbid disorders in problem and pathological gambling: Systematic review and meta-analysis of population surveys. Addiction, 106(3), 490-498. http://dx.doi.org/10.1111/j.1360$0443.2010 .03300 \mathrm{x}$

Milosevic, A., \& Ledgerwood, D.M. (2010). The subtyping of pathological gambling: A comprehensive review. Clinical Psychology Review, 30(8), 988-998. http://dx.doi. org/10.1016/j.cpr.2010.06.013 (doi: S0272-7358(10)00107-8 [pii]).

Muthén, L. K., \& Muthén, B. O. (1998-2010). Mplus user's guide (Sixth Edition ). Los Angeles, CA: Muthén \& Muthén.

N.O.R.C. National Opinion Research Center (1999). Gambling impact and behavior study, Report to the National Gambling Impact Study Commission.

Nylund, K., Asparouhov, T., \& Muthen, B. (2007). Deciding on the number of classes in latent class analysis and growth mixture modeling: A Monte Carlo simulation study. Structural Equation Modeling: A Multidisciplinary Journal, 14(4), 535-569.

Petry, N. M., Stinson, F. S., \& Grant, B. F. (2005). Comorbidity of DSM-IV pathological gambling and other psychiatric disorders: Results from the National Epidemiologic Survey on Alcohol and Related Conditions. Journal of Clinical Psychiatry, 66(5), 564-574.

Piero, A. (2010). Personality correlates of impulsivity in subjects with generalized anxiety disorders. Comprehensive Psychiatry, 51(5), 538-545. http://dx.doi.org/10.1016/j. comppsych.2010.02.003 (doi: S0010-440X(10)00006-4 [pii]).

Sarisoy, G., Kacar, O. F., Pazvantoglu, O., Ozturk, A., Korkmaz, I. Z., \& Kocamanoglu, B. (2012). Temperament and character traits in patients with bipolar disorder and associations with attempted suicide. Comprehensive Psychiatry. http://dx.doi.org/10.1016/ j.comppsych.2012.05.002 (doi: S0010-440X(12)00080-6 [pii]).

Slutske, W. S., Caspi, A., Moffitt, T. E., \& Poulton, R. (2005). Personality and problem gambling: A prospective study of a birth cohort of young adults. Archives of General Psychiatry, 62(7), 769-775.

Steel, Z., \& Blaszczynski, A. (1996). The factorial structure of pathological gambling. Journal of Gambling Studies, 12, 3-20.

Tavares, H., Gentil, V., Oliveira, C., \& Tavares, A. (1999). Jogadores patologicos, uma revisao: Psicopatologia, quadro clinico e tratamento [Pathological gamblers, a review of psychopathology, clinical presentation and treatment]. Revista de Psiquiatria Clinica, 26(4), 179-187.

Turner, N. E., Jain, U., Spence, W., \& Zangeneh, M. (2008). Pathways to pathological gambling: Component analysis of variables related to pathological gambling. International Gambling Studies, 8(3), 281-298.

Vachon, D.D., \& Bagby, R. M. (2009). Pathological gambling subtypes. Psychological Assessment, 21(4), 608-615. http://dx.doi.org/10.1037/a0016846 (doi: 2009-22537014 [pii]).

Wing, J. K., Babor, T., Brugha, T., Burke, J., Cooper, J. E., \& Giel, R. (1990). SCAN. Schedules for Clinical Assessment in Neuropsychiatry. Archives of General Psychiatry, 47(6), 589-593.

Yoo, H. J., Kim, M., Ha, J. H., Chung, A., Sim, M. E., \& Kim, S. J. (2006). Biogenetic temperament and character and attention deficit hyperactivity disorder in Korean children. Psychopathology, 39(1), 25-31. http://dx.doi.org/10.1159/000089660 (doi: 89660 [pii]). 